\title{
أثر القيم الجمالية للنحت الصرحى بالحدائق العاهة فى تنمية الذوق العام *
}

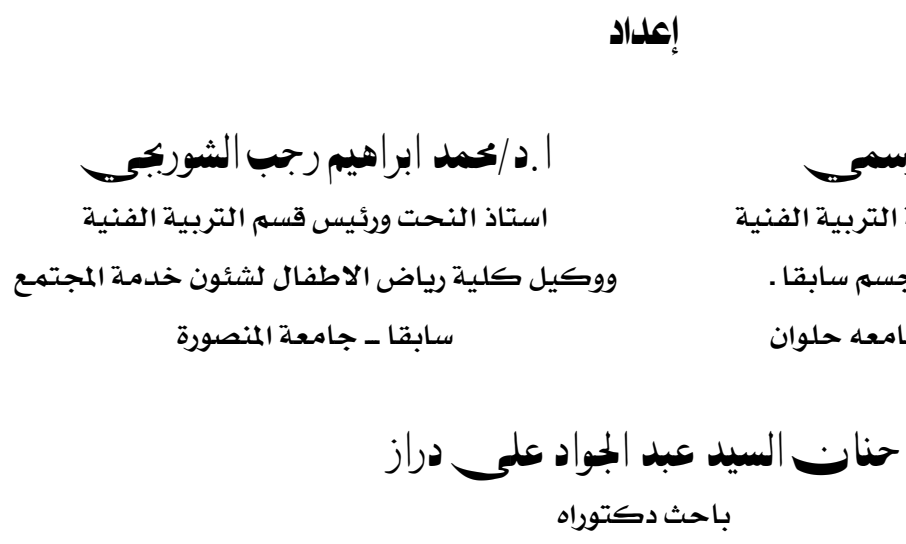

إعلداد

| .د/محمد ابر|هيب رجب الشوربجحسـ

استاذ النحت ورئيس قسم التربية الفنية لهبية

ووكيل كلية رياض الاطفال لشئون خدمة المجتمع المعادئ

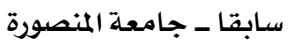

حنات السيد عبد الجواد علحـ مراز

باحث دكتوراه

مجلة بحوث التربية النوعية ـ جامعة المنصورة

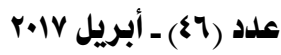

" بحث مستل من رسالة دكتوراه 


\section{أثر القيم البمالية للنمت الصرحى بالصدائق العاهة فى تنمية الذوق العام

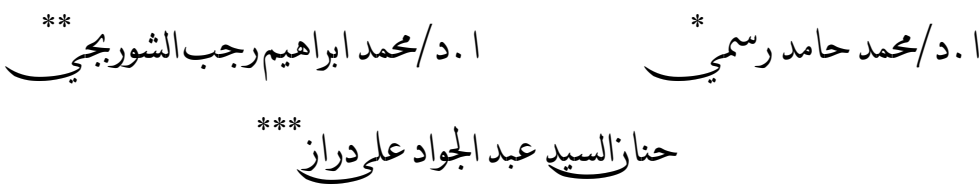

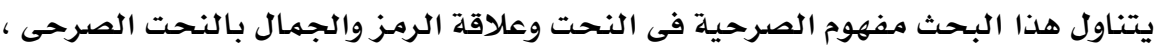

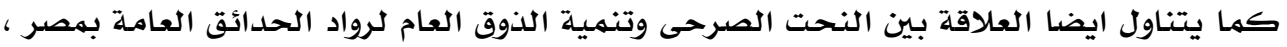

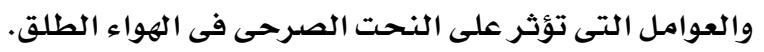

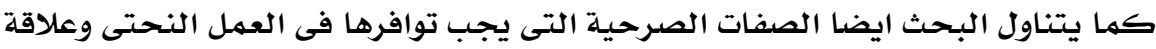

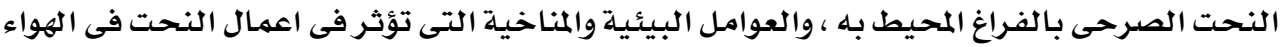
الطلق.

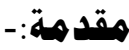

ان الفن والبيئة عنصران لا يفترقان ،كل منهما يؤثر فى الاخر ويتأثر بـه ،فالبيئة تمثل هنا

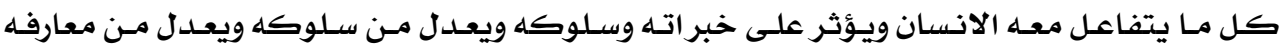

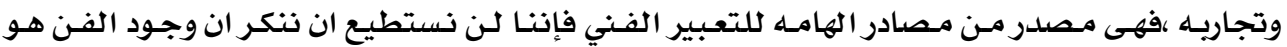

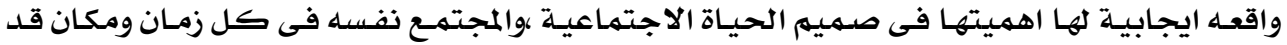

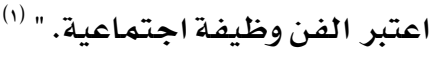
ويعتبر فن النحت هو اقرب الفنون للأعمال الفنيـة بالأمـاكن العامـة ،والعلاقـة التى يمكن

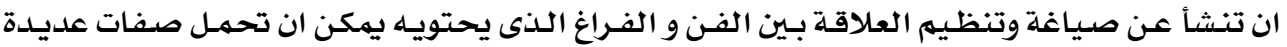

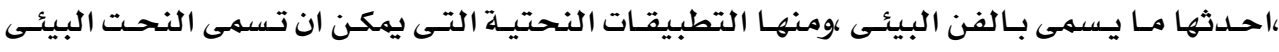

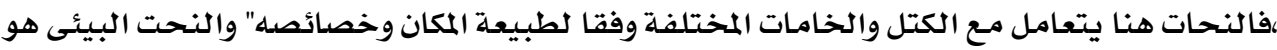

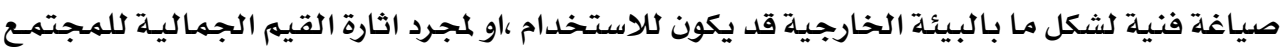

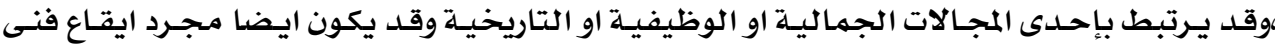

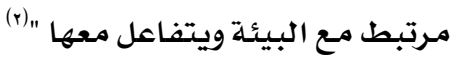

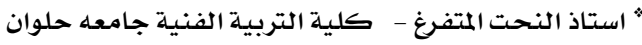

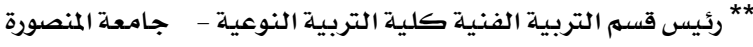

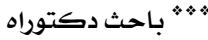

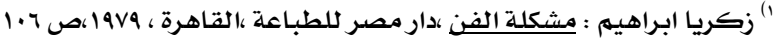
, 3/12/2010http://www.alwaqt.com ${ }^{(r)}$ 


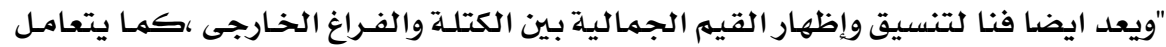

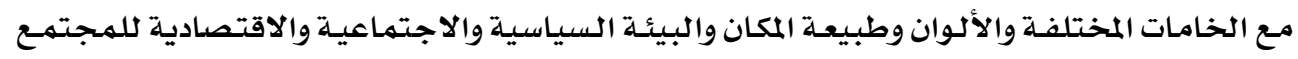

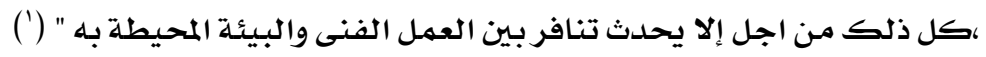

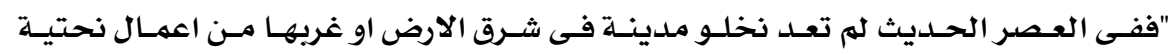

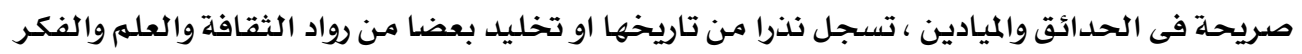

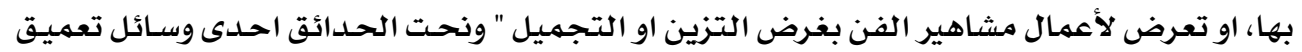

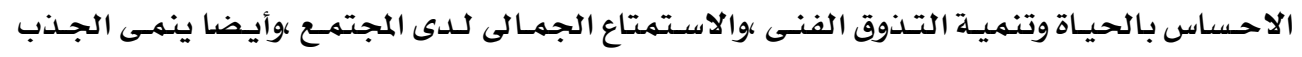

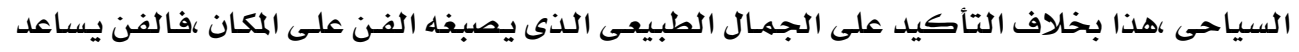

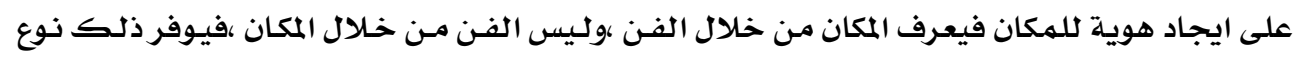

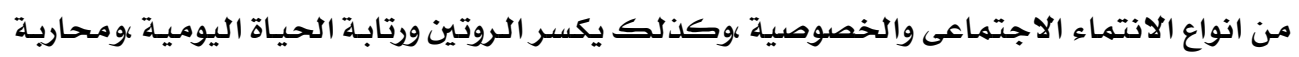

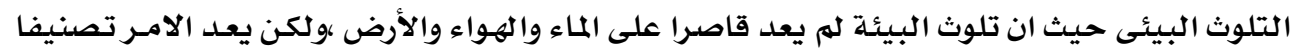

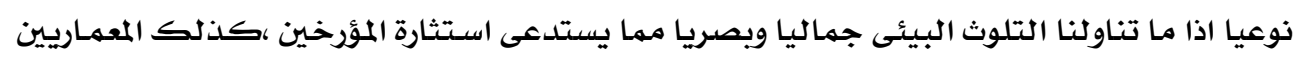

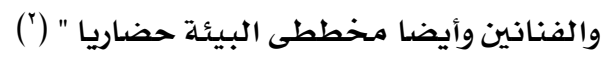

وتماثيل الحدائق على الرغم من اشتراكها مع تماثيل الميادين فى الفراغ الخـارجى ،إلا انها

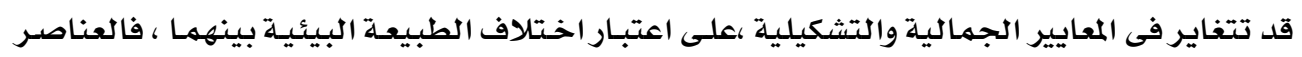

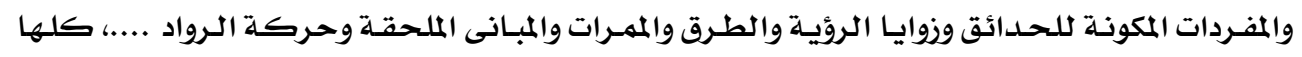

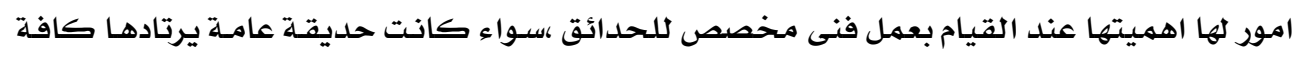

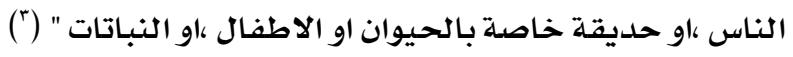

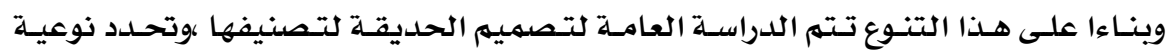

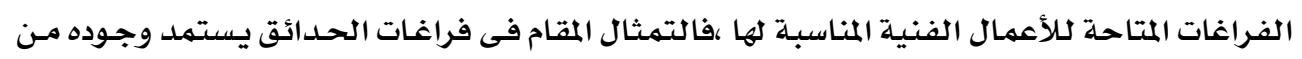

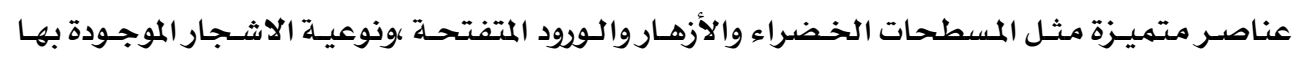

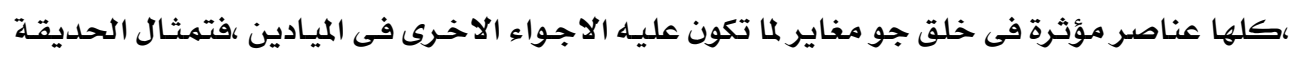

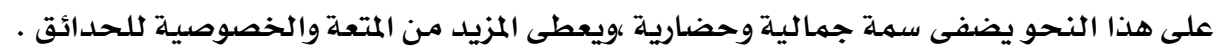

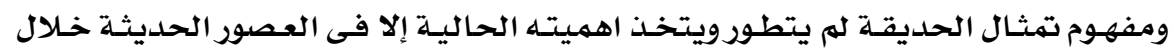

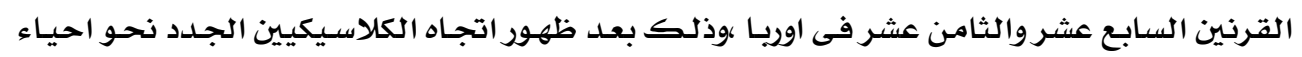

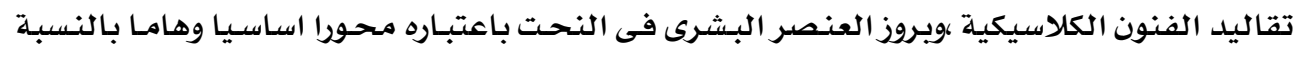

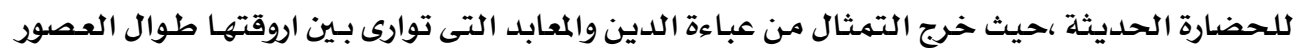

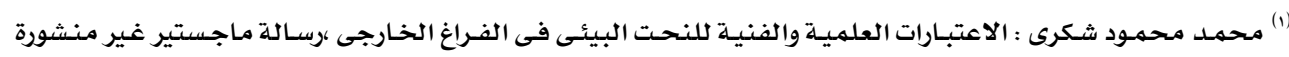

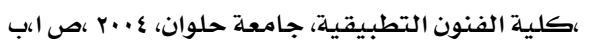

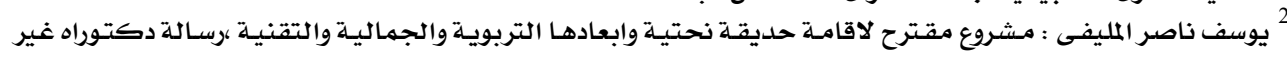

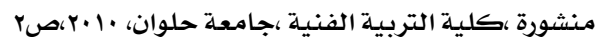

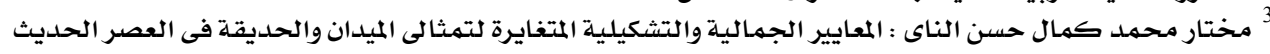

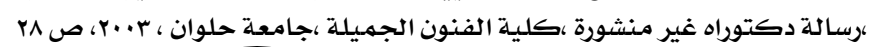




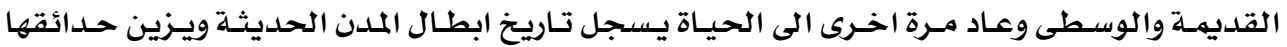

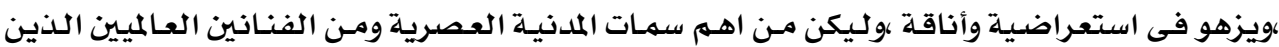

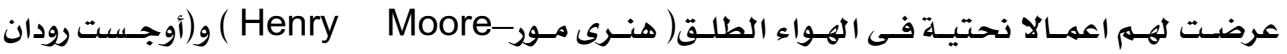

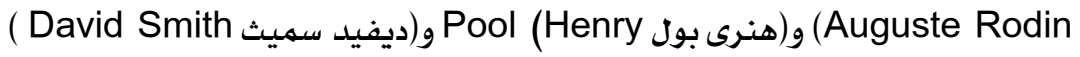

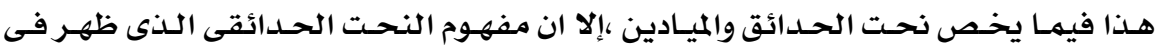

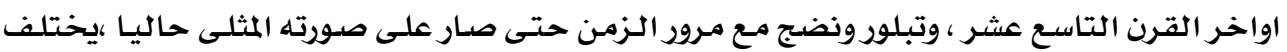

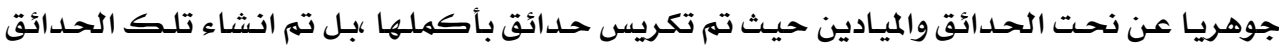

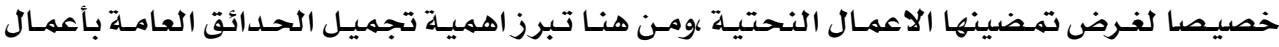

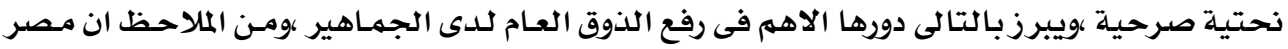

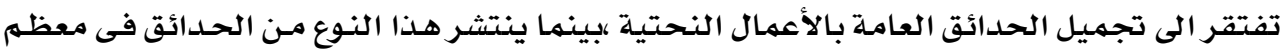
البـلاد المتقدمة . مشكلة البحث

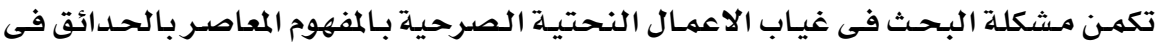

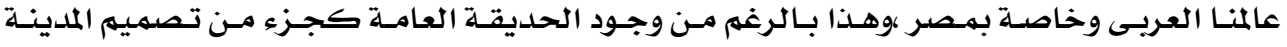

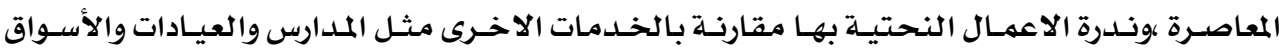

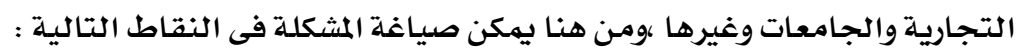
ا ـ كيف يمكن الاستفادة من الابعاد الفلسفية والجماليـة للنحت الصرحى فى تجميل الحـدائق

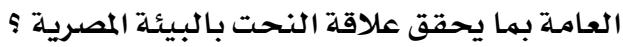

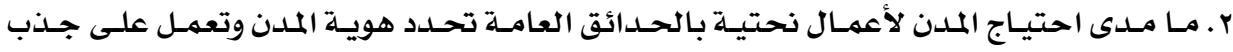

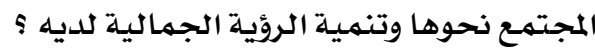
اهمية البمث :

$$
\text { ترجيع اهمية البحث الحالى الى : }
$$

ا ـ ادراك رواد الحدائق العامة للصياغات الشكلية والجمالية ،والتقنيات المتنوعة للأعمال النحتيـة

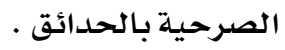
r. التعرف على مختارات من اعمال النحـاتين المعروضـة بالحـدائق العامـة ، واشهـر الفنـانين الدين

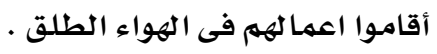

r. اثراء الذوق العام بالقيهم الجمالية للنحت من خلال الاعمال النحتية بالحدائق.

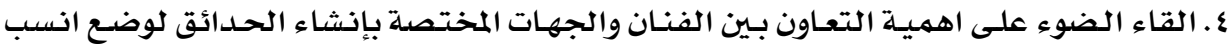

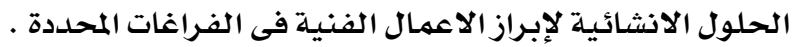




$$
\text { اهدافٔ البهـ البرالقيم الجمالية للنحت الصرحى بالحلائق العامة فى تنمية الذوق العام }
$$

ا ـ دراسـة النظم والمعايير التى تحكم تصميهم الحـدائق العامـة ، وإيجـاد رؤيسة فنيـة وعلميـة لـصياغة

الاعمال النحتية بما يناسب تصميم الحديقة وفق هوية مصريـة خالصدة ץ . دراسـة الابعـاد الفلسفية والجمالية لفن النحت الحديث ، لإيجاد مداخل جديدة تتناسـب وطرق

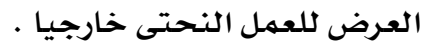
r. القاء الضوء على القيهم الفنيـة والفكريـة التى تترتب عليها تشكيل وجـدان المجتمهـع ، والإفـادة منها فى انثاء اعمال نحتيـة بالحداءئق العامـة .

$$
\text { تقتصر الدراسـة فى هذا البحث على : }
$$

• تناول الاعمال النحتيـة التى اقيهت فى الهواء الطلق بالدراسـة وخاصدة بالحدائق العامـة

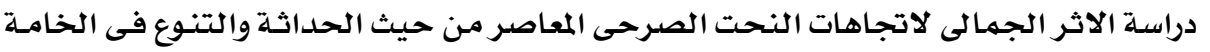

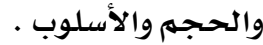

• عمل نماذج نحتيـة ثلاثية الابعاد تصلح للعرض بالحدائق العامـة .

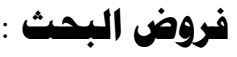

$$
\text { تفترض الباحثة ما يلى : }
$$

ا.وجود علاقة بين الابعاد الفلسفية والجمالية للنحت الصرحى وبـين تجميل الحدائق العامـة . r. توجد علاقة جمالية بين النحت الصرحى والبيئة المحيطة بـه فى الحدائق العامـة فى مصدر.

\section{إجزاs|ت البحث :}

\section{اولا مناهج البحث :}

تتبـع البـاحثة المنهج الوصفى التحليلى فى دراسـة النقاط التالية :

أ_ دراسـة اعمال النحت الصـرحى المعاصـر بـالحدائق العامـة فى مصر والعاله فى مصـر والعاله . ب - دراسـة التقنيات والفلسفات الجمالية لتلك الاعمال. ج - دراسـة تحليلية لمختارات من اعمال الفنانيين المرتبطة اعمالهم بنحت الحدائق . د ـ دراسلة عوامل الارتقاء بالبيئة المصرية جماليا . ثاثيا ادوات البحث : تتبـع الباحثة المنهج التجريبـى فى الاتى :

ا ـ قياس اثر الاعمال النحتية على الحدائق جماليا . r . قياس نتائج التجربـة الذاتية وتحليلها احصائيا . 


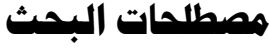 \\ النجت الصرحى :}

إن الــرحية كهـا وردت فـى الموسـوعات والقـواميس هـى صـفة مـن صـفات بعـض المبـاني

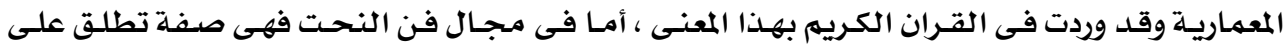

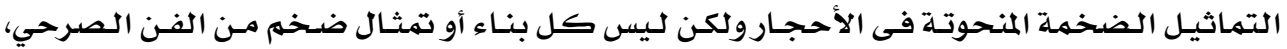
فالضخامـة هى الجـانب المادي فقط فى الفن الصـرحي ، لكن الأثر العاطفي أو الانفعالي الذذى يحققـهـ

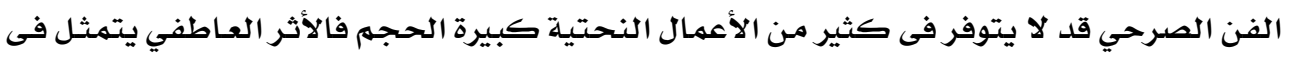

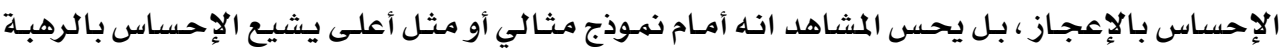

والإعجـازوالتبـجيل (')

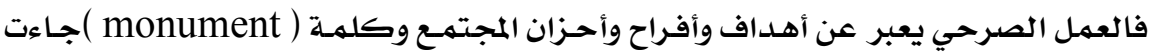

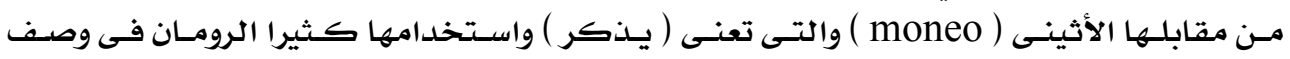

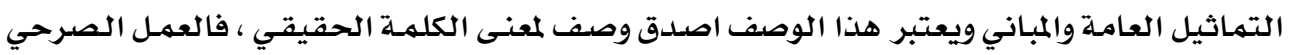

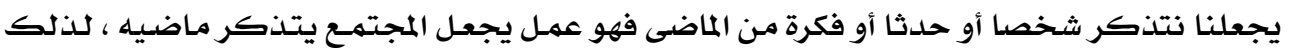

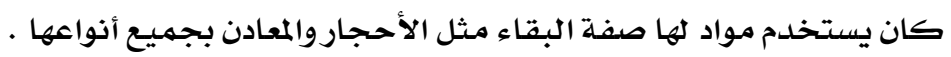

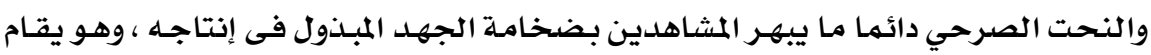

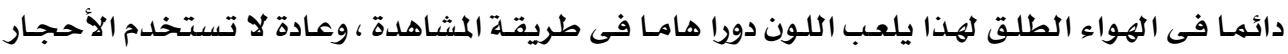

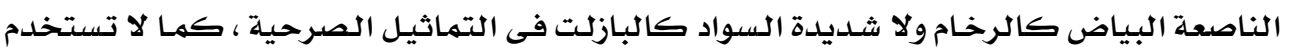

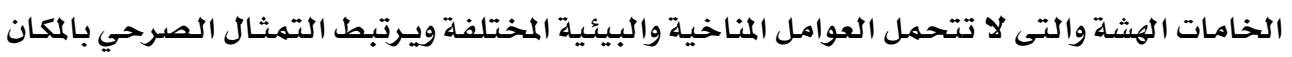

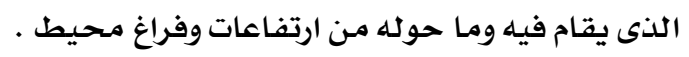

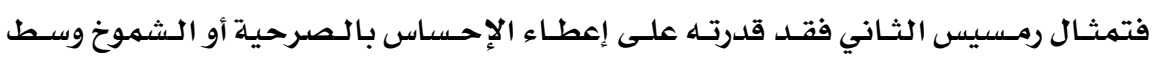

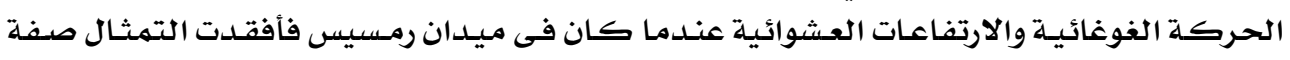

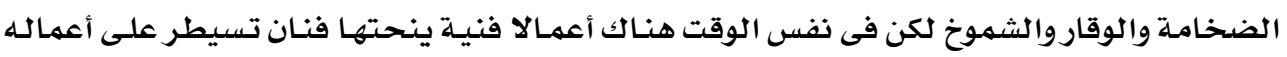

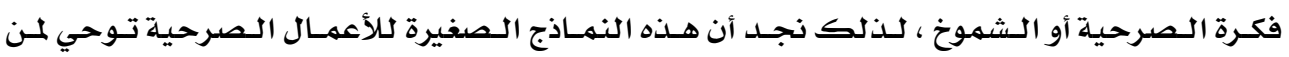

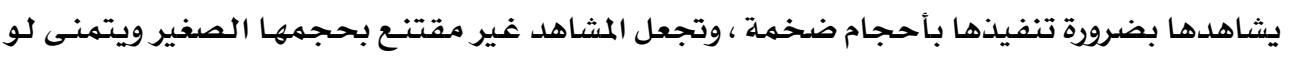

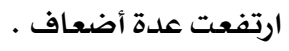

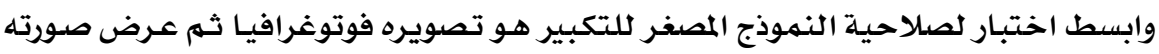

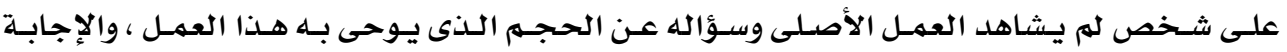

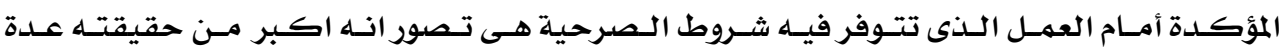

أضعاف"() (

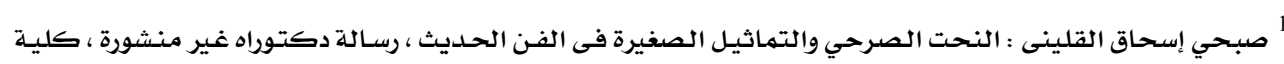

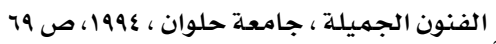

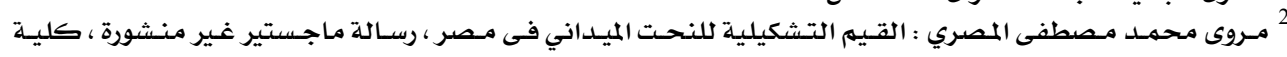

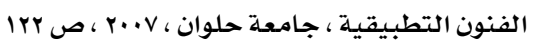


191 -191راسة عزة عبد الحميد حلمى

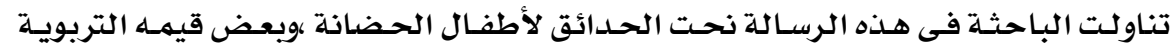

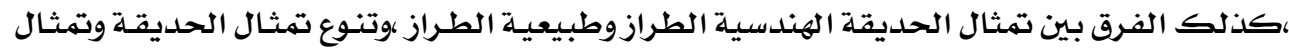

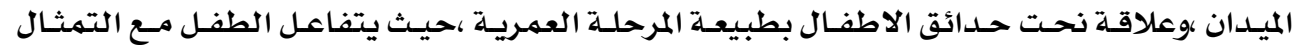

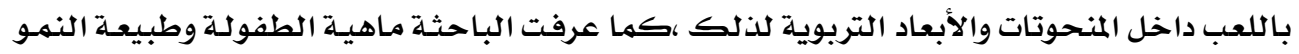

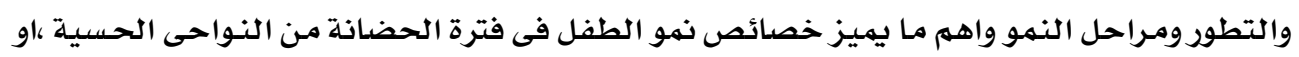

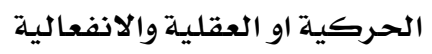

تفيـد هـذه الرسـالة البحـث الحـالى فى التعـرف على نحست الحـدائق وتطوره وطبيعـة تمثال الحديقة من حيث المواصفات والشروط والأسس.

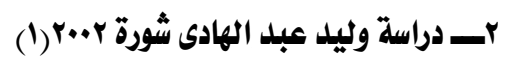

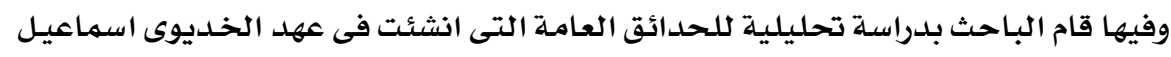

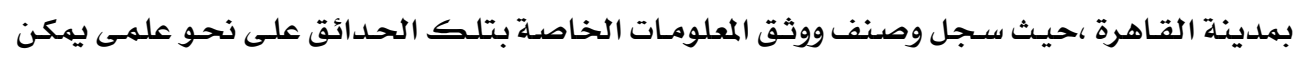

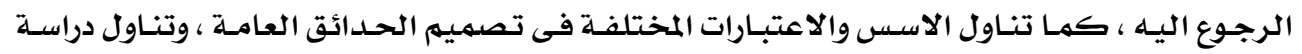

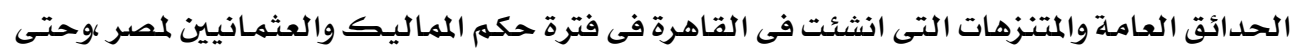

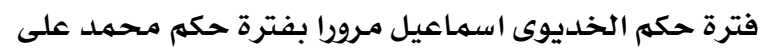
تفيد الدراسـة البحث الحـالى في التعـرف على دور الحـدائق العامـة مـن النـواحى التاريخيـة

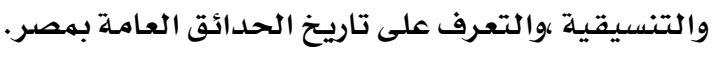

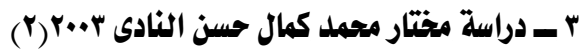

تناول فيها الباحث الاختلافات الجوهرية لحركة المحاور والاتجاهات بين الميادين والحسدائق

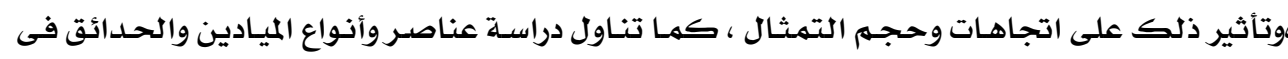

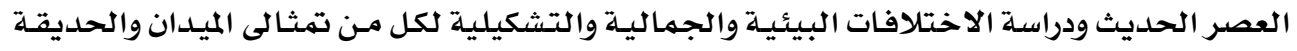

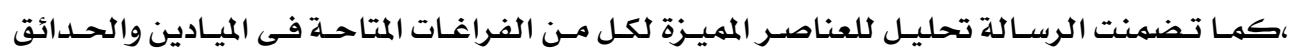

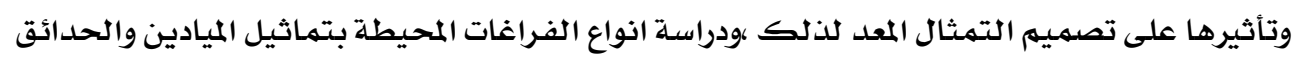
تفيـد هـذه الدراسـة البحث الحسالى فى التعـرف على المعـايير الجماليـة والتشكيلية لتمثثال

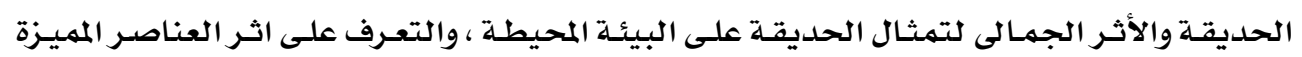

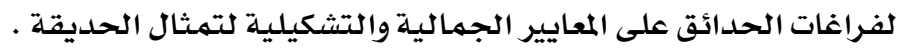

") وليد عبد الهادى شورة : دراسـة تحليلية للحدائق العامـة التى انشئت فى عهد الخديوى اسماعيل بمدينـة القـاهرة ،رسـالة

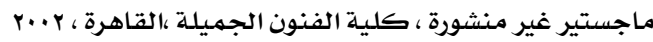

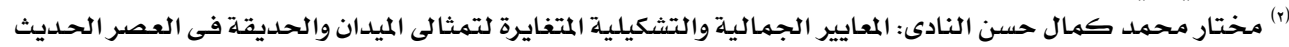

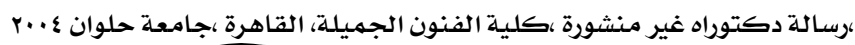




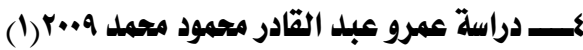

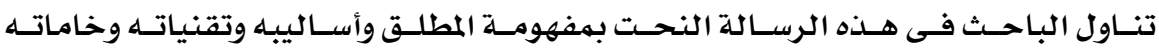

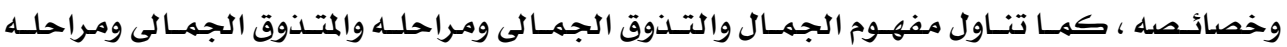

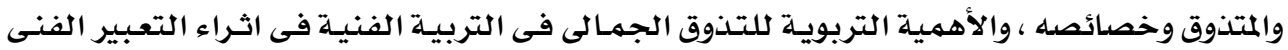
فى مجال النحت

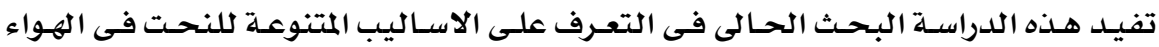

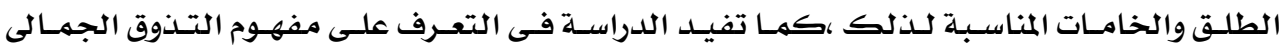

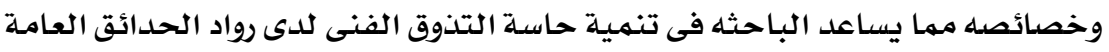

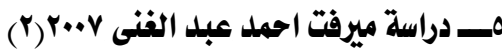

وتناولـت الباحثـة في هـذه الرسـالة المفـاهيهم الفلسفيـة والجماليـة لفـن العمليـات والبيئسة

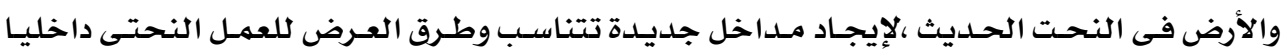

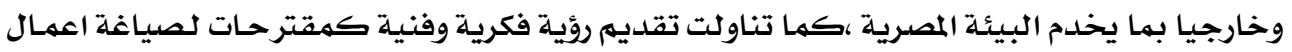

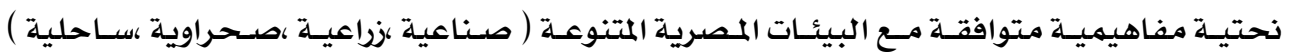

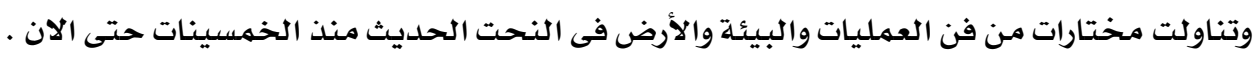

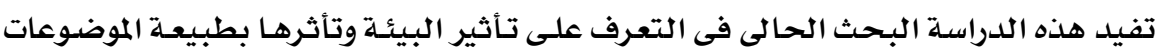

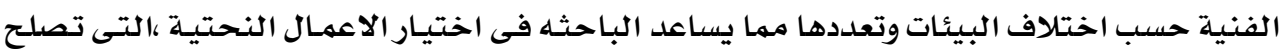

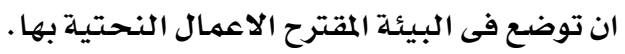

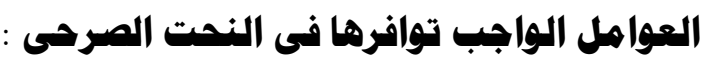

اـ ضخامة العمل النحتي الصرحي أو الإيحاء بها :

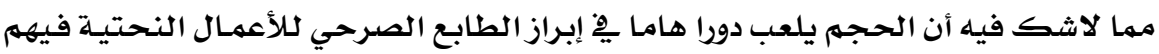

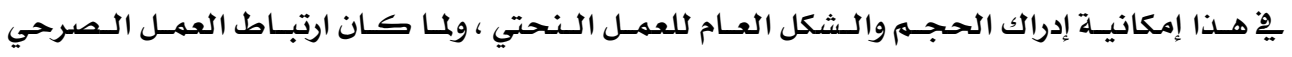

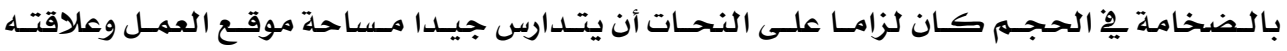

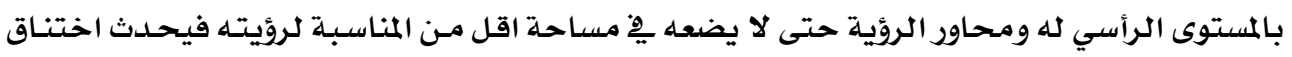
للشكل ويفقد هويته الصرحية المرأسية

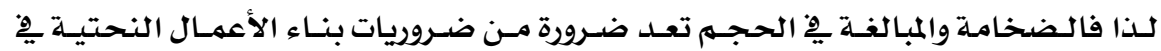

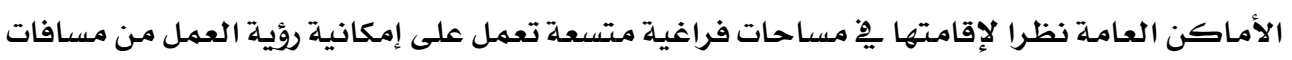

بعيدة بوضوح

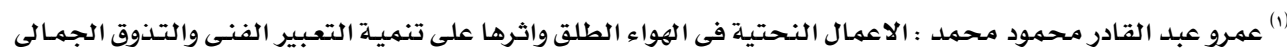

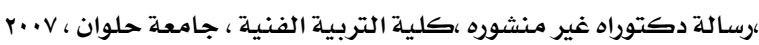

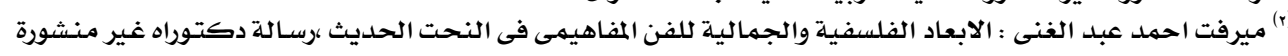

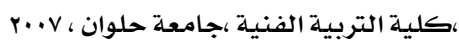




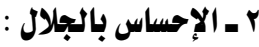

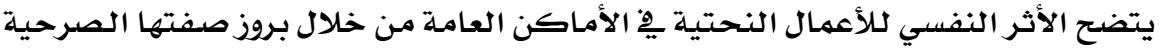

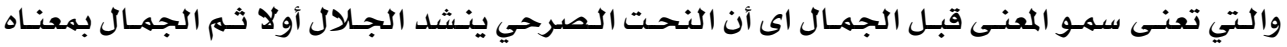

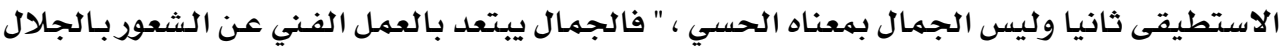

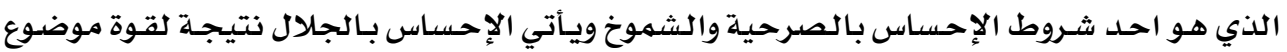

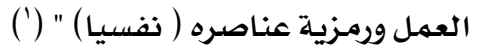

\section{ويتحقق الإحساس بالجلال هِّ العمل النحتي من خلال :}

أ. استقامسة الخطوط الراسية واتجاهها إلى أعلي فالدوائر والأقواس توحي بالليونة والأنوثة والرقة

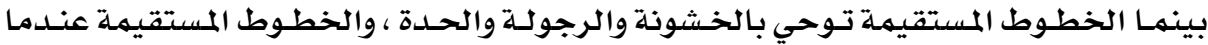

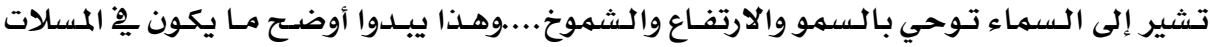

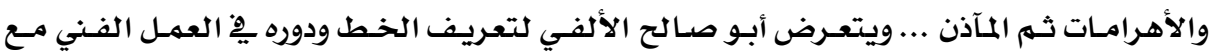

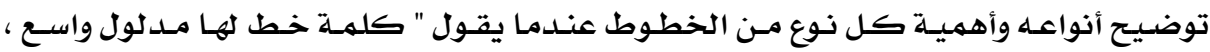

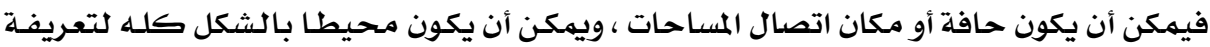

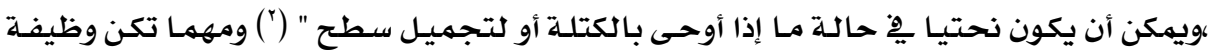

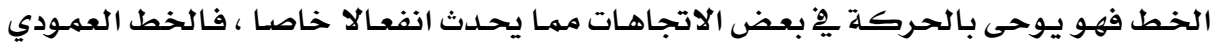

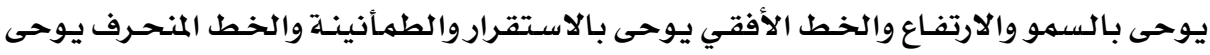

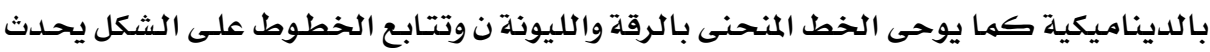

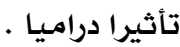

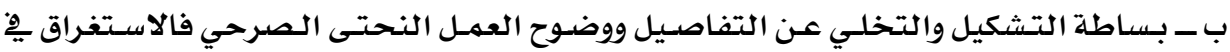

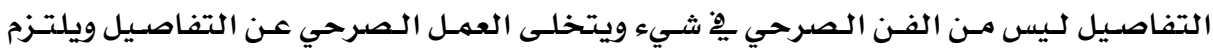

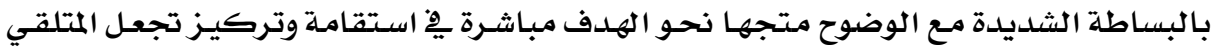

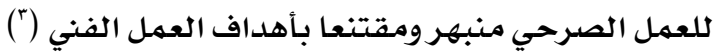
فالنحت الصرحي صريح يعلن بوضوح وقوة عن هدفه فإذا كان العمل الفـني ضـخما وخطوطـه

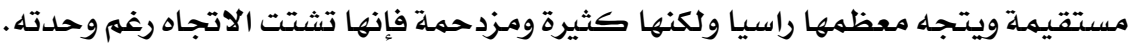

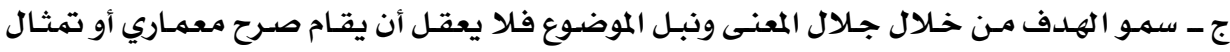

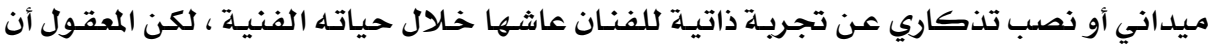

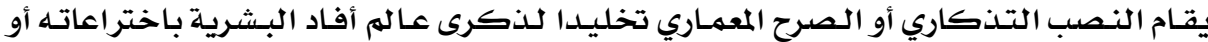

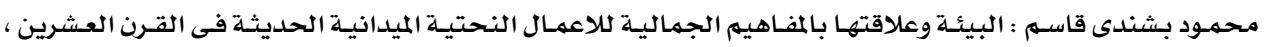

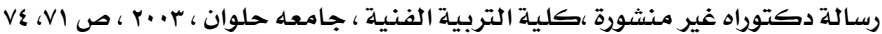

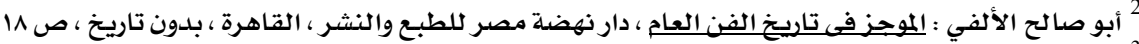

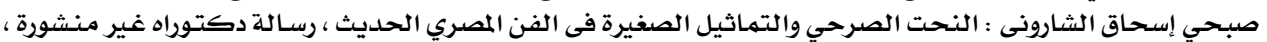

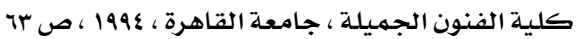


جنود ضـحوا بـأرواحهم لتحريـروطنهم مثل النصب التذكاري الذذي أقامسه الفنـان سـامي رافـع تخليدا (لأرواح شهداء حرب سو ) ) انه هدف سـامي ونبيل يعتز بـه كل مصدري ويجله ويحترمسه .

\section{الرهز والجمهال وعلاقتتهمها بالنمت الصرحي :}

إن النحات ِِّ القرن العشرين ، قد كشف عن حقيقة الرمـز سواء بصورة مبـاشرة أو بالإيحاء

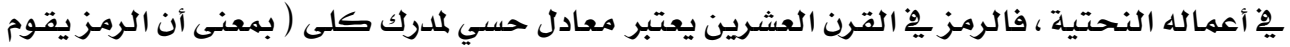
مقام شيء آخر ـِ صلـة ، إما تكون واضحة أو غامضـة ، أو جزئية ) فالصلة بـين الرمز وما يرمـز إليـه قد تكون صلـة غامضـة تحتاج إلى تحليل أو تفكير لكشف مـا بينهمـا مـن علاقـات ، وارتبـاطـات أو تكون صسلة

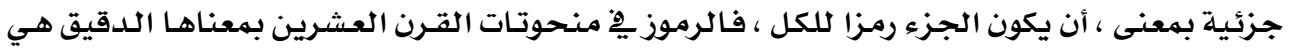
التي يكتفي فيها على مجرد الدلالنة ، بحيث يكون هناك طرفان فقط ، طرف العلاقة الدالـة مـن جهـة وطرف الشيء المدلول عليه من جهة أخرى ، بل يضاف إلى مجرد الدلالة شحنـة عاطفية من نوع معـين

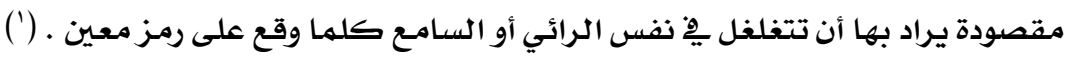

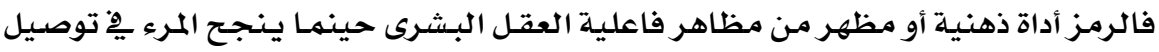
فكرتـه إلى الآخـرين عن طريـق بعض الرمـوز ، فإننـا نقـول عنـه انه أحسـن التعـبير عن تلـك الفكـرة ،

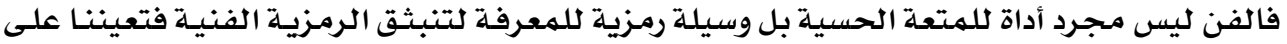
المعرفة العميقة لتلك الحياة البـاطنية ، فالمشاهد يعتمد عند تذوقه للعمل الفني على الإدراك الحسي ، فيقوم بعمليات فكرية استـلاليه ، فهو يدرك الشكل وهو رمز يبدعه الفنان وينشده بـدون أن يشير بـه

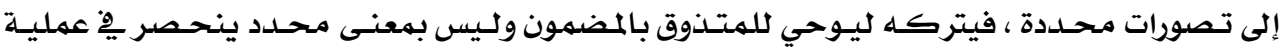

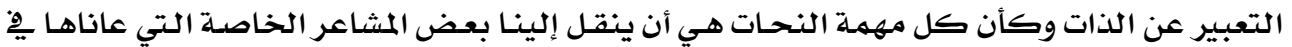
حياته الوجدانيـة ، وإنها تنحصر مهمهة النحات يف التعبير عن المعـاني العميقـة بطريقـة رمزيـة لا تأتى إنى بأي وسيلة أخرى من وسائل التعبير.

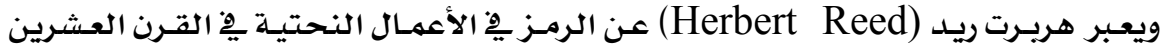

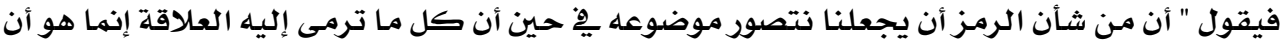

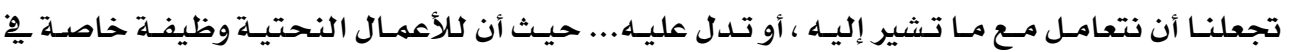

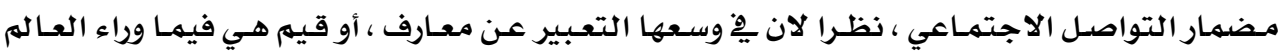

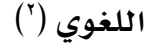

لذلك فالعمل الصرحي يتطلب من النحات أن يعطى لمجتمعهـ رموزا تعبر عن أفكارهم ، وان

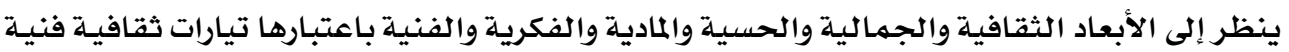

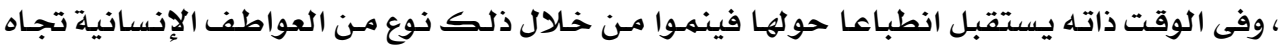

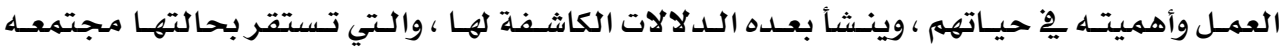

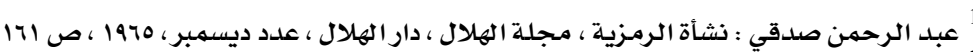

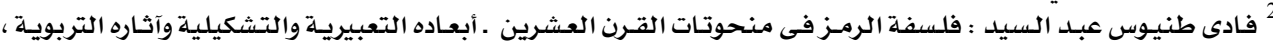

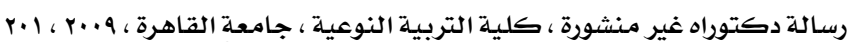




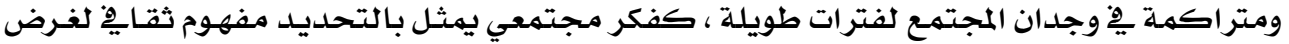

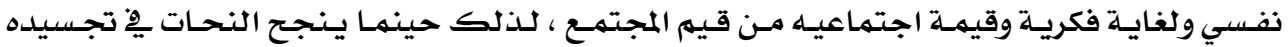

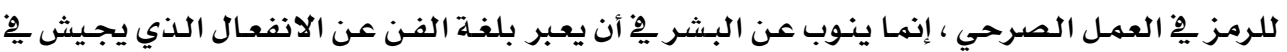

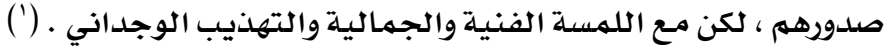

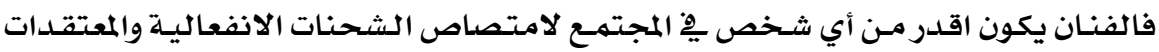

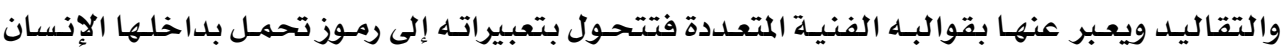

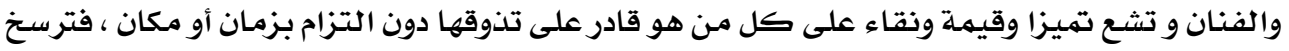

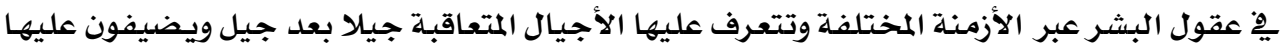

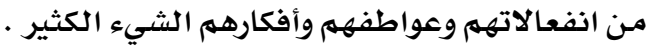

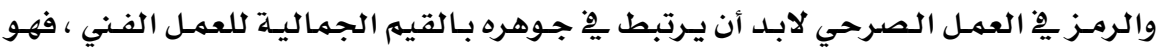

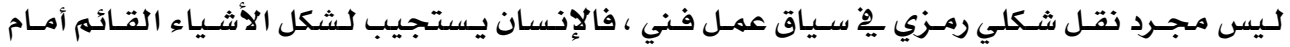

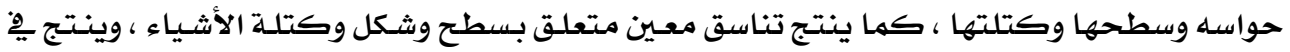

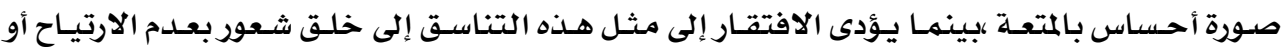

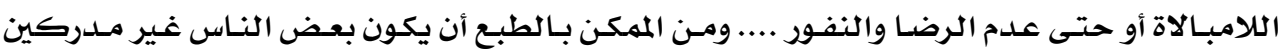

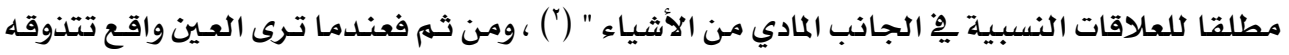

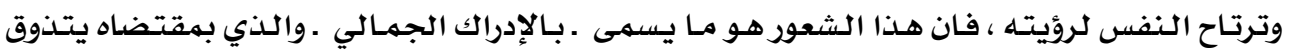

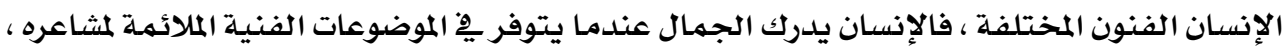

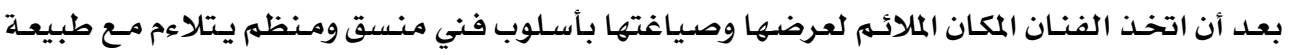

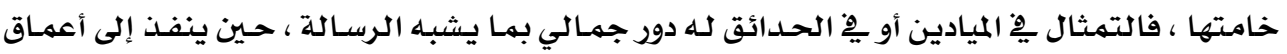

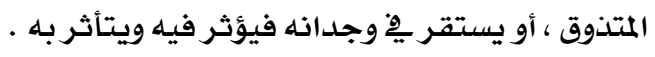

ويقول بدر الدين أبو غازي ِِّ هذا السياق " إن رسالة التمثال لا تتحقق حـين يـروق أنظارنـا ،

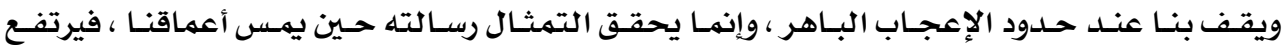

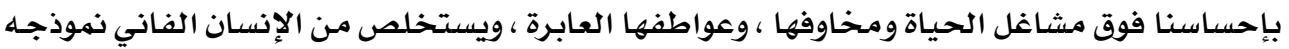

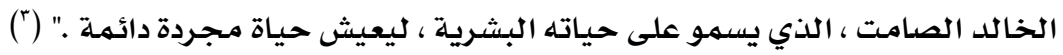

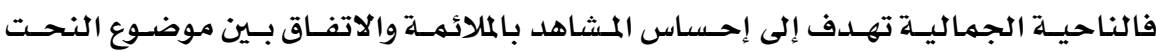

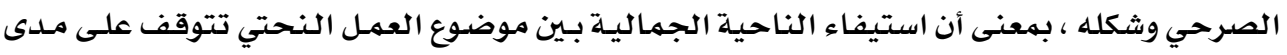

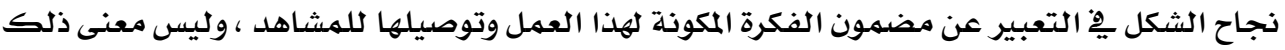

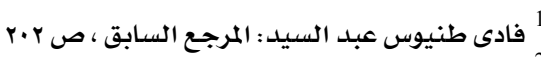

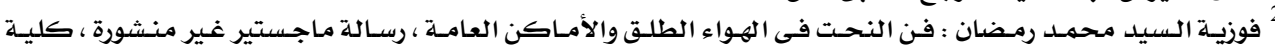

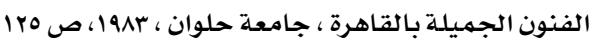

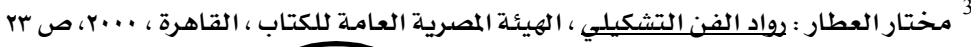


إضـافة الزخرفة أو الألوان ، أو اى إضـافات لا تلـزم للتعبير عن المضمهون تزيـــ مـن قيمتهه ، بـل ممكن أن

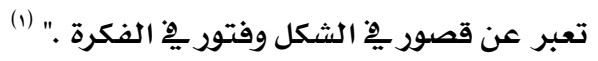

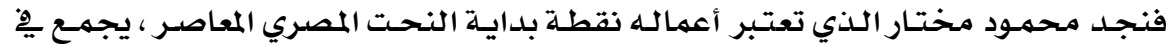

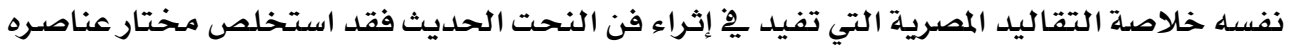

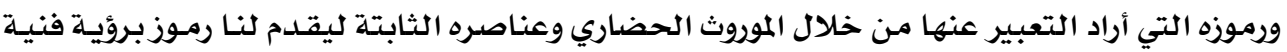

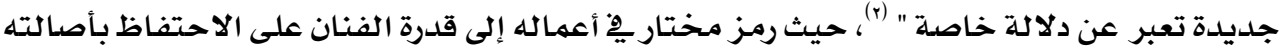

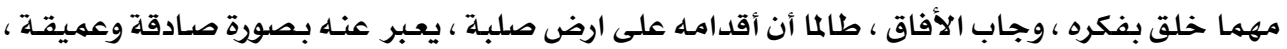

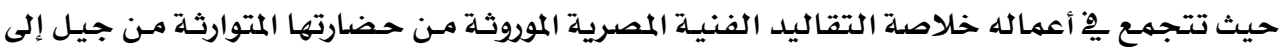

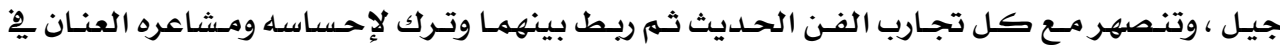

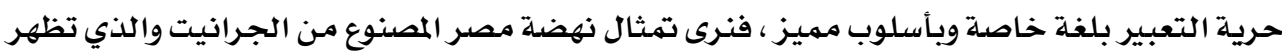

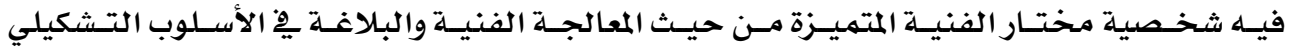

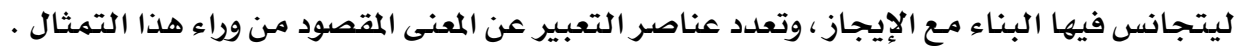

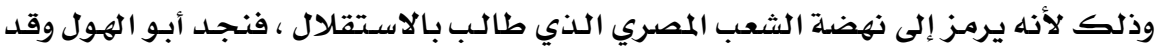

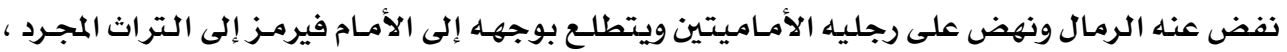

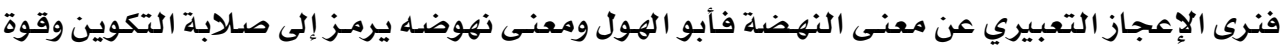

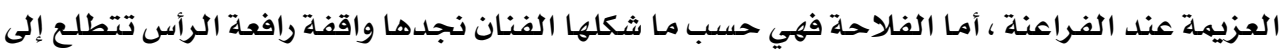

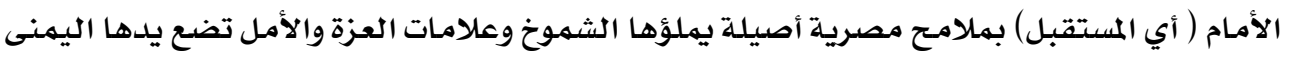

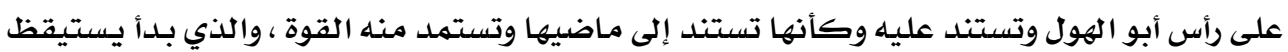

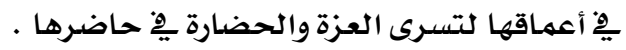

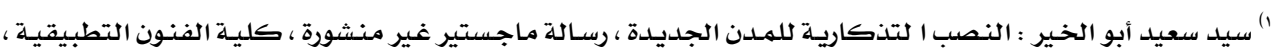

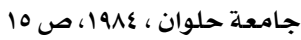

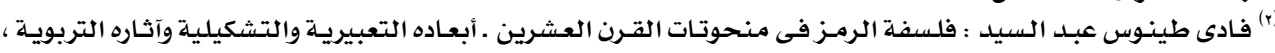

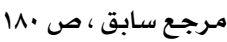


בب = القرالقيم الجمالية للنحت الصرحى بالحدائق العامة فى تنمية الذوق العام

التجربة العمطية للباحثة:
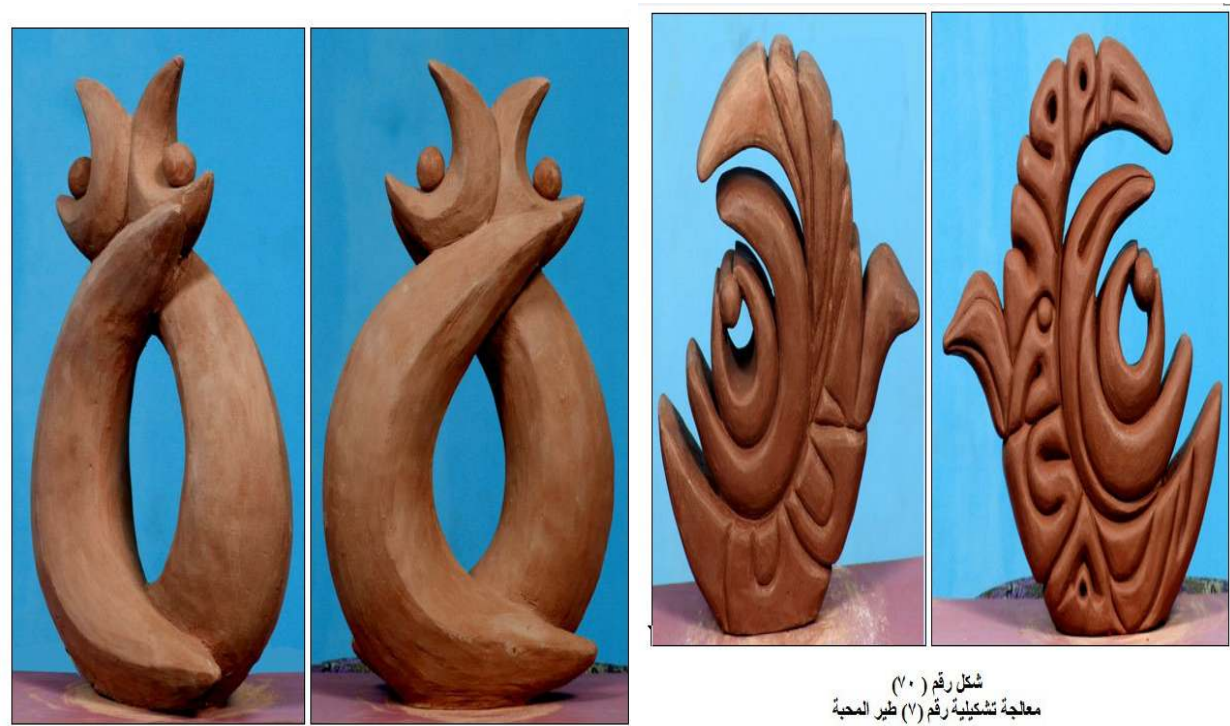

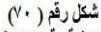

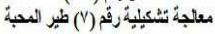
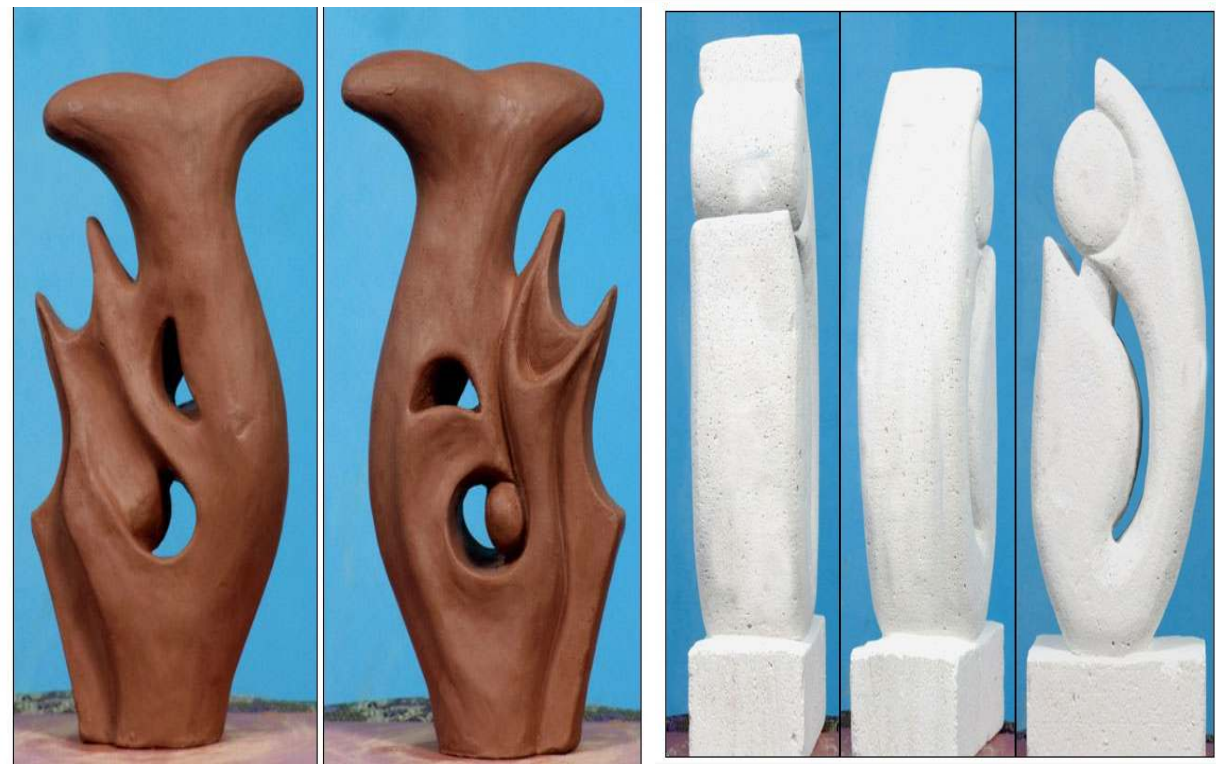
النتائج والتوصيات :

اولا:النتائج

توصلت الدارسة من خلال الدراسة النظرية والتطبيقية الى :

• هناك فلسفة جمالية خاصدة بالتماثيل المعدة لتنفيذها فى الحدائق العامـة

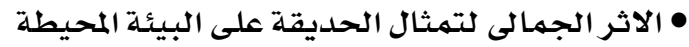

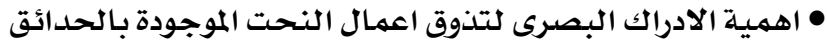

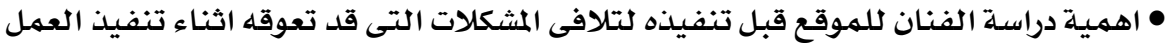

ثانيا:التوصيات

• دراسـة العناصر المميزة للموقع او الحديقة المراد تجميلها بالتماثيل دراسـة دقيقـة ويفضل اتبـاع

$$
\text { طرق منهجية في ذلك }
$$

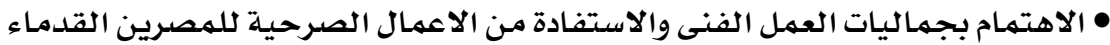

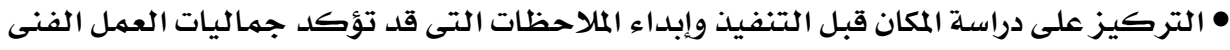

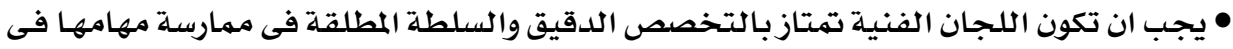

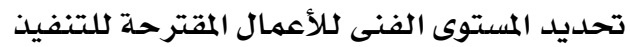

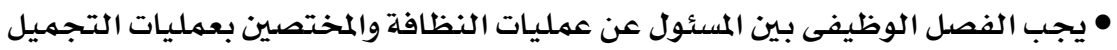

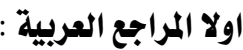

1. أبو صالح الألفي : الموحز في تاريخ الفن العام ، دار نهضة مصر للطبع والنشر ، القاهرة ، بدون تاريخ

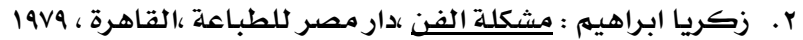

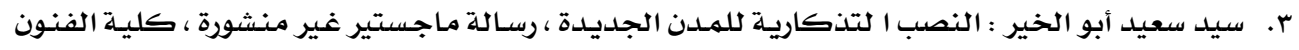

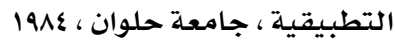

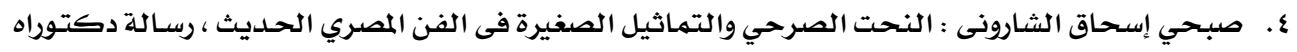

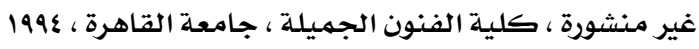

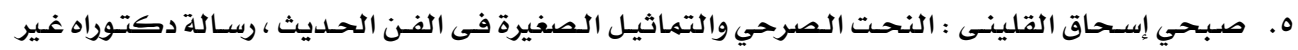
منشورة ، كلية الفنون الجميلة ، جامعة حلوان ، ع 199

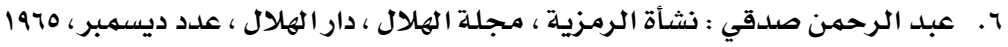

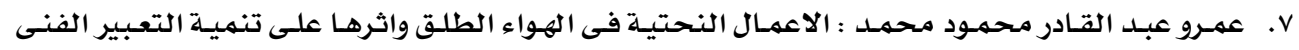

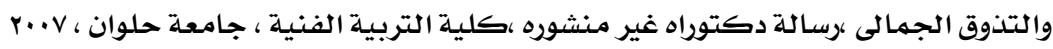

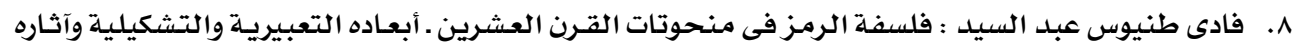

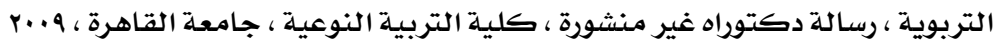


9. فوزيـة السيد محمد رمضان : فن النحت فى الهواء الطلق والأماكن العامة ، رسالة ماجستير غير منشورة ،

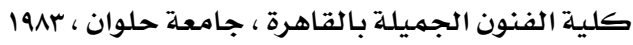

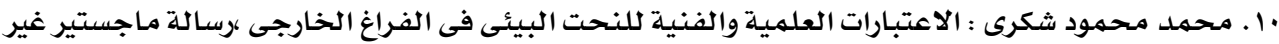

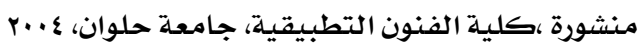
1ا ـ محمود بشندى قاسهم : البيئة وعلاقتها بالمفاهيم الجماليـة للاعمال النحتيـة الميدانية الحديثة فى القرن

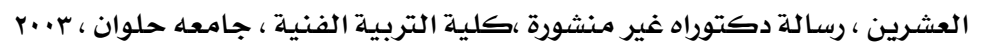

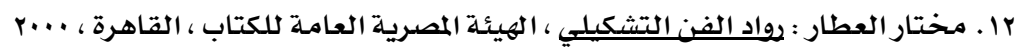

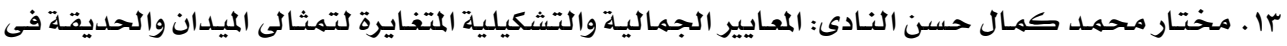

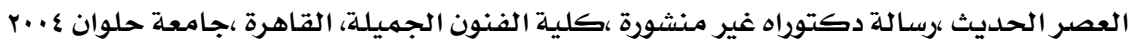

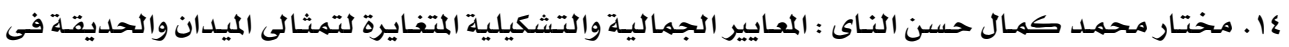

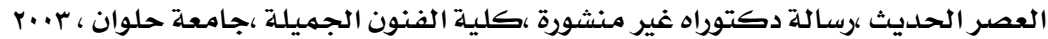

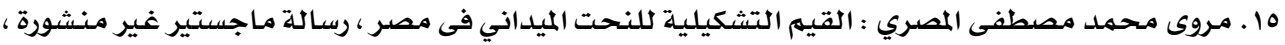

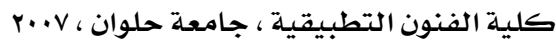

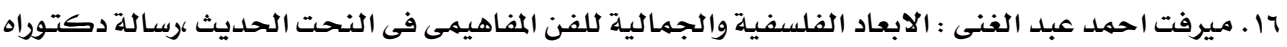

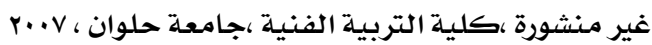

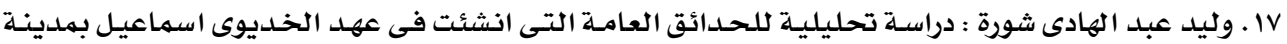

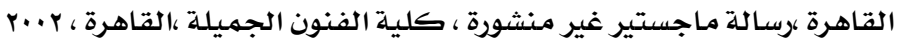

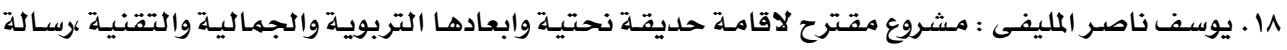

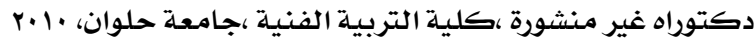

19. http://www.alwaqt.com , 3/12/2010 


\section{Abstract}

This research discuss the concept of sculpture and The relationship between monumental sculpture and the relationship of the symbol of beauty and monumental sculpture.

It also discuss the relation between the monumental sculpture and the development of General tasting of public gardens in Egypt, It also discuss the factors which affection of the monumental sculpture in the open air.

This research also discuss the Monumental epithets which must be find in sculpture work, and its relation with monumental sculpture in space, This research also discuss the Environmental and climatic factors which affection of sculpture in the open air. 